\title{
ABSORPTION OF ESCHERICHIA COLI ENDOTOXIN BY THE NEONATAL PIG
}

\author{
B. J. Shreeve AND J. R. Thomlinson \\ Department of Veterinary Pathology, University of Liverpool
}

\section{Plate VI}

EARLIER experiments (Shreeve and Thomlinson, 1970a, 1971a) have shown that colostrum-deprived piglets from sows immunised with hen-egg albumin or with an antigenic extract of Escherichia coli may be hypersensitive to the antigen used for immunisation. Lesions that developed in these piglets after intravenous challenge with the homologous antigen closely resembled those that occur in natural cases of disease associated with $E$. coli. This condition of the baby piglet has many features in common with oedema disease and gastro-enteritis of the older pig (Shreeve and Thomlinson, 1970b), and the lesions bear some resemblance to those associated with anaphylactic shock (Thomlinson and Buxton, 1962, 1963). Involvement of an anaphylactic mechanism in the pathogenesis of $E$. coli disease would necessitate rapid absorption of $E$. coli endotoxin from the gastro-intestinal tract. Symptoms of anaphylactic shock have been shown to develop in guinea-pigs $5 \mathrm{~min}$. after oral dosage with an antigenic extract of E. coli O139 (Thomlinson and Buxton, 1962) and in piglets within $6 \mathrm{~min}$. of oral challenge with a similar extract of E. coli O138:K81(B) (Shreeve and Thomlinson, 1971a). Using a haemagglutination-inhibition test, Miler et al. (1964) were able to demonstrate $E$. coli endotoxin in various organs from piglets after oral administration. In the present experiments, absorption of $E$. coli endotoxin was studied by means of an immunofluorescence technique.

\section{MATERIALS AND METHODS}

Origin of animals. Colostrum-deprived piglets were obtained from Large White sows, as described previously (Shreeve and Thomlinson, 1970a), and were used immediately after birth. The guinea-pigs employed in the experiments were approximately $300 \mathrm{~g}$ body weight and had been reared under conventional conditions.

Preparation of E. coli extract. A frozen and thawed extract of E. coli serotype 0138: K81(B) was produced by the method of Erskine, Sojka and Lloyd (1957) and stored at $-30^{\circ} \mathrm{C}$. The same batch of extract was used throughout the experiments.

Challenge of animals. (a) Intravenous injection. Intravenous injections were given to guinea-pigs by way of the metatarsal veins and to piglets into the anterior vena cava (MacKenzie, 1961). The E. coli extract, either undiluted or at dilutions of 1 in 10 and 1 in 100 , was injected into 13 guinea-pigs at doses of 0.5 and $1 \mathrm{ml}$ and into nine colostrum-deprived piglets at a dose of $3 \mathrm{ml}$. Another two colostrum-deprived piglets were each given an injection of $9 \mathrm{ml}$ of undiluted $E$. coli extract. The guinea-pigs were killed at 10 or $30 \mathrm{~min}$. and the piglets at $15 \mathrm{~min}$. or $4 \mathrm{hr}$ after injection. (b) Oral dosage. $5 \mathrm{ml}$ of undiluted $E$. coli

Received 1 May 1971; accepted 15 June 1971

J. MED. MICROBIOL.-VOL. 5 (1972) 
extract was administered orally to each of ten colostrum-deprived piglets by introducing the extract into the posterior part of the buccal cavity. From this group, two piglets were killed $1,5,10,30$ and $120 \mathrm{~min}$. after they were dosed. Sterile normal saline in 5-ml amounts was administered orally by the same method to five control piglets, which were killed at comparable times.

Preparation and labelling of antisera. Pig antiserum to the crude E. coli extract was prepared as described previously (Shreeve and Thomlinson, 1971b).

Anti-pig serum was prepared in a sheep by injecting whole pig serum intravenously in doses of 2, 5, 5 and $10 \mathrm{ml}$ on alternate days. This course of injections was repeated twice at intervals of 10 days and blood was collected 10 days after the final injection.

Crude gamma-globulin was prepared from the sheep anti-pig serum (AG) by the method already described (Shreeve and Thomlinson, 1971b) and was conjugated with fluorescein isothiocyanate (Nairn, 1962). Unreacted fluorescent material was removed by gel filtration with Sephadex G-25. To reduce non-specific staining from conjugated normal serum proteins, the conjugates were absorbed with sheep liver powder (Coons and Kaplan, 1950). After absorption, both gamma-globulins were adjusted to their original volumes by concentration against polyethylene glycol and preserved with merthiolate at a final concentration of 1 in 10,000 .

Preparation and staining of tissue sections. Blocks of the fundic region of the stomach, the small intestine, liver and spleen were snap-frozen in isopentane cooled on solid carbon dioxide, and stored at $-70^{\circ} \mathrm{C}$. Cryostat sections, $4.5 \mu \mathrm{m}$ thick, were fixed in 2-octanol at $-30^{\circ} \mathrm{C}$ (Maxwell, Ward and Nairn, 1966).

Tissue sections from experimentally inoculated and from control animals were washed five times for $5 \mathrm{~min}$. each with phosphate-buffered saline $(\mathrm{pH} 7 \cdot 1)$ before they were stained at room temperature by the indirect immunofluorescence technique (Nairn). The sections from the experimental animals were stained with pig antiserum to $E$. coli extract and sheep anti-pig-globulin-fluorescein conjugate (FITC) to detect the presence of coliform endotoxin in the cells. Comparable sections were treated with normal pig serum and FITC, with the specific pig anti-serum, blocking sheep anti-pig globulin (AG) and FITC, and with FITC alone, as staining controls; the first two controls showed obviously reduced fluorescence, as compared with positive sections, and the third control negative fluorescence. An additional control consisted of a section from animals given only saline and stained with the pig antiserum and FITC; this also gave negative fluorescence. After staining, sections were dipped briefly in de-ion:sed water to remove salts, and examined in the dry state. Similar sections were stained with haematoxylin and eosin.

Bacteriological methods. Stomach and intestinal contents, liver and spleen were cultured aerobically on 7 per cent. sheep blood agar, and on MacConkey agar, at $37^{\circ} \mathrm{C}$ for $18 \mathrm{hr}$, to determine whether any of the recognised pathogenic serotypes of $E$. coli were present.

\section{RESULTS}

\section{Absorption of $E$. coli endotoxin after intravenous injection}

Guinea-pigs. No specific fluorescence was seen in livers or spleens from any of the guinea-pigs.

Piglets. Specific fluorescence was observed in only one piglet. This animal had been given an injection of $9 \mathrm{ml}$ of $E$. coli extract and was killed $15 \mathrm{~min}$. later. Fluorescence was distributed throughout the liver and spleen. No fluorescence was observed in sections from the piglet killed $4 \mathrm{hr}$ after receiving a similar dose of extract or from the other piglets given an injection of $3 \mathrm{ml}$ of extract either undiluted or diluted 1 in 10 or 1 in 100 . Incoordination and trembling were noted in all piglets after the injection, and vomiting and diarrhoea occurred in those kept alive for $4 \mathrm{hr}$ (Shreeve and Thomlinson, 1971a). 


\section{E. COLI ENDOTOXIN IN PIGLETS}

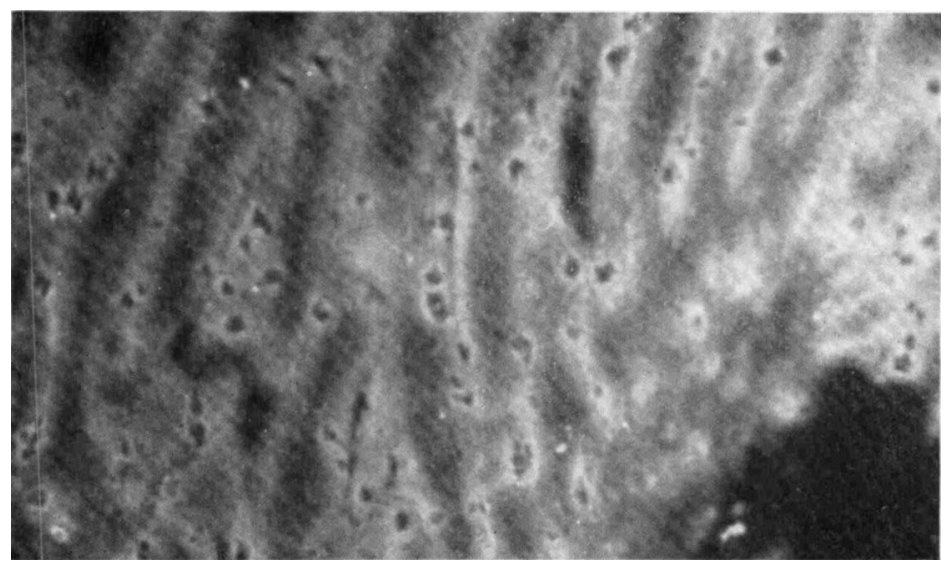

FIG. 1.-Specific fluorescence in the small intestine of a piglet orally challenged with $5 \mathrm{ml}$ of E. coli $\mathrm{O} 138: \mathrm{K} 81$ (B) extract and killed $5 \mathrm{~min}$. after challenge. Section stained with pig antiserum to $E$. coli O138:K81 (B) extract and sheep anti-pig conjugate. x. 60 .

FIG. 2.-As fig. 1. × c. 240 .
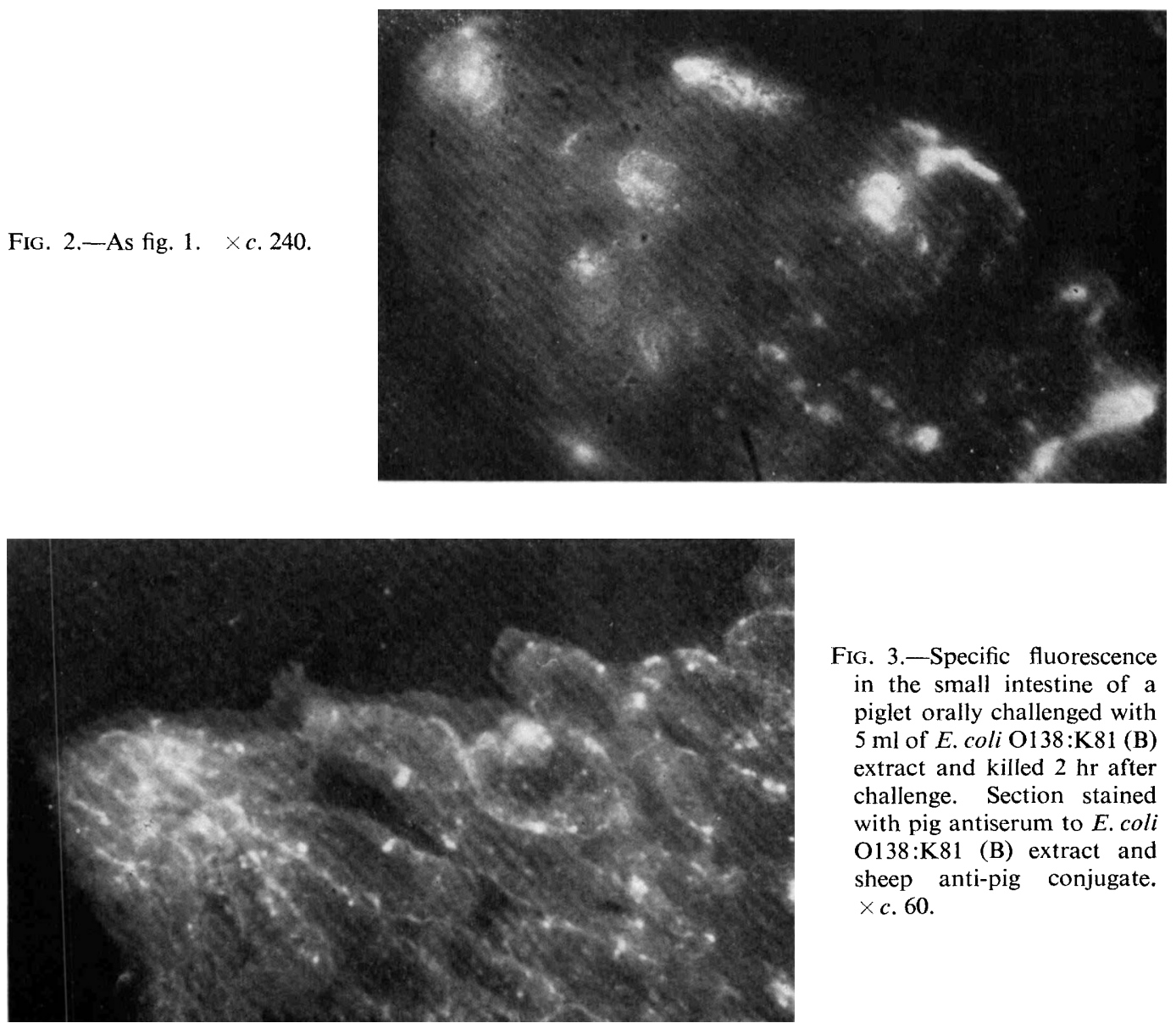

FIG. 3.-Specific fluorescence in the small intestine of a piglet orally challenged with $5 \mathrm{ml}$ of E. coli O138:K81 (B) extract and killed $2 \mathrm{hr}$ after challenge. Section stained with pig antiserum to $E$. coli O138:K81 (B) extract and sheep anti-pig conjugate. $\times c .60$. 


\section{Absorption of E. coli endotoxin after oral dosage}

Specifically stained areas were visible in the stomach and small intestine from piglets killed at all times (from 1 to $120 \mathrm{~min}$.) after dosing. Within 5 min. the extract appeared on the surface of the gastric mucosa and around the edges of the intestinal villi (fig. 1). High-power observations suggested that the extract was located within the superficial villous cells $5 \mathrm{~min}$. after dosing (fig. 2). In later cases deeper absorption was detected (fig. 3). Specific fluorescence was detected in the spleen, where it appeared to be generally distributed throughout the red pulp 5, 10,30 and $120 \mathrm{~min}$. after dosing. Comparison with haematoxylinand-eosin-stained sections confirmed the histological location. No fluorescence was detected at any time in liver sections. Mild signs of shock were noted in all piglets that remained alive $6 \mathrm{~min}$. after oral challenge (Shreeve and Thomlinson, 1971a). No symptoms were observed in piglets given sterile normal saline.

\section{Bacteriological findings}

No pathogenic serotypes of $E$. coli were detected in any of the specimens and tissues examined.

\section{Discussion}

The presence of $E$. coli antigen in the spleens of piglets $5 \mathrm{~min}$. after a bacterial extract had been given orally confirmed that $E$. coli antigen is absorbed rapidly from the gastro-intestinal tract. There was no evidence of antigen in the spleens of piglets killed $1 \mathrm{~min}$. after oral administration and it is significant that a demonstrable concentration was present in the spleen only marginally earlier than the time when endotoxin shock would have been expected to develop. Shreeve and Thomlinson (1971a) observed clinical signs of endotoxin shock $6 \mathrm{~min}$. after piglets were challenged orally with E. coli extract, and in the present experiments similar clinical signs developed in piglets that were allowed to live longer than $5 \mathrm{~min}$. Anaphylactic shock has been observed in guinea-pigs $5 \mathrm{~min}$. after oral challenge with a similar extract of $E$. coli $\mathrm{O} 139$ (Thomlinson and Buxton, 1962). These observations support the concept that lesions produced after endotoxin is introduced into the alimentary tract are the result of a generalised reaction rather than a local effect on the gut wall. The occurrence of specific fluorescence within the superficial cells of villi in the stomach and small intestine indicates that absorption occurs from both these organs.

Specific fluorescence was observed in the liver of a piglet that had received a large dose of E. coli extract by the intravenous route and was killed $15 \mathrm{~min}$. later, but not in one that was killed $4 \mathrm{hr}$ after a similar dose. No specific fluorescence was observed in livers from any of the piglets to which $E$. coli extract had been administered orally. It is possible that the intravenous administration of a relatively large amount of endotoxin will result in its transient appearance in all organs until it is taken up completely by those that contain a relatively large amount of reticulo-endothelial tissue (Ravin et al., 1960). In the present experiments the spleen was a constant site of specific 
fluorescence once absorption had occurred. Miler et al. (1964) used a haemagglutination-inhibition test and were able to demonstrate $E$. coli endotoxin in livers from piglets 30 and $60 \mathrm{~min}$. after intravenous injection and $24 \mathrm{hr}$ after it was introduced into the lumen of the intestine. They estimated that approximately $1 / 6000$ th of the original amount administered by the intra-intestinal route was present in the liver. It is possible that the sensitivity of the method they used differed from that in the present experiments. On the other hand, Ravin et al., using a haemagglutination-inhibition test for endotoxin in normal and shocked rabbits, and Buxton and Davies (1963), in a similar investigation of chickens experimentally infected with Salmonella gallinarum, found considerable variation in the polysaccharide content of the various organs in individual animals.

Miler et al. were unable to detect endotoxin in organs from bacteria-free piglets that had been deliberately contaminated with a single non-pathogenic strain of $E$. coli and concluded that the endotoxin may have been destroyed or the amount released by the bacteria may have been too small to be detected by the method used. Since there is evidence that different serotypes of $E$. coli differ in their ability to establish themselves in the anterior small intestine of the pig (De Alwis, 1970), it is possible that the strain employed did not persist at this level for a sufficiently long period to release detectable amounts of endotoxin. The attachment of large numbers of pathogenic $E$. coli to the mucosa of the small intestine has been observed in porcine colibacillosis (Arbuckle, 1970) and it is likely that under these circumstances endotoxin would be released (Crutchley, Marsh and Cameron, 1967) and absorbed in relatively large amounts. It has been postulated that after the selective multiplication of one serotype, endotoxin from that serotype may be absorbed rapidly and cause disease (Shreeve and Thomlinson, 1970a). The results of the present experiments confirm that such absorption of endotoxin can occur.

\section{SUMMARY}

After oral dosage of neonatal piglets with Escherichia coli O138:K81(B) extract, antigen was detected within superficial cells of the small intestine after $1 \mathrm{~min}$. and in the spleen after $5 \mathrm{~min}$. The significance of these findings for $E$. coli disease of young piglets is discussed.

We acknowledge the financial support of the Pig Industry Development Authority. Thanks are due to Professor D. L. Hughes for his helpful advice and criticism, and to Mr G. Weston and Mrs M. W. Harling for the photomicrographs and technical assistance.

\section{REFERENCES}

Arbuckle, J. B. R. 1970. The location of Escherichia coli in the pig intestine. J. Med. Microbiol., 3, 333.

Buxton, A., AND Davies, Jean M. 1963. Studies on immunity and pathogenesis of salmonellosis. II. Antibody production and accumulation of bacterial polysaccharide in the tissues of chickens infected with Salmonella gallinarum. Immunology, 6, 530.

CoONs, A. H., AND KaPLAN, M. H. 1950. Localization of antigen in tissue cells. II. Improvements in a method for the detection of antigen by means of fluorescent antibody. J. Exp. Med., 91, 1. 
Crutchley, M. J., Marsh, D. G., AND CAmeron, J. 1967. Free endotoxin. Nature, Lond., 214, 1052.

De AlwIS, M. C. L. 1970. Some factors influencing the survival and multiplication of pathogenic Escherichia coli in the gastro-intestinal tract of the pig. Ph.D. Thesis, Univ. Liverpool.

ERSKINE, R. G., SojKA, W. J., AND Lloyd, M. K. 1957. The experimental reproduction of a syndrome indistinguishable from oedema disease. Vet. Rec., 69, 301.

MACKenzIE, A. 1961. Observations on anterior vena cava venepuncture in the pig. Vet.Rec., 73, 435.

Maxwell, A., Ward, H. A., AND NaIRN, R. C. 1966. Freezing in an isopentane liquid nitrogen mixture and storage in 2-octanol: technical improvements for immunofluorescence. Stain Technol., 41, 305.

Miler, I., Kostka, J., Simek, L., AND Lanc, A. 1964. Fate of endotoxin in the intestine of newborn bacteria-free piglets monocontaminated with Escherichia coli. Folia microbiol., Praha, 9, 277.

NAIRN, R. C. 1962. Fluorescent protein tracing, Edinburgh and London.

Ravin, H. A., Rowley, D., Jenkins, C., AND Fine, J. 1960. On the absorption of bacterial endotoxin from the gastro-intestinal tract of the normal and shocked animal. J. Exp. Med., 112, 783.

Shreeve, B. J., AND Thomlinson, J. R. 1970a. Hypersensitivity in young piglets: its relation to the pathogenesis of Escherichia coli disease. J. Med. Microbiol., 3, 377.

Shreeve, B. J., AND Thomlinson, J. R. 1970b. Escherichia coli disease in the piglet. A pathological and bacteriological investigation. Br. Vet. J., 126, 444.

SHREEVE, B. J., AND Thomlinson, J. R. 1971a. Hypersensitivity of young piglets to Escherichia coli endotoxin. J. Med. Microbiol., 4, 307.

Shreeve, B. J., AND ThomLinson, J. R. 1971b. Transfer of Escherichia coli antibodies from sow to piglet. J. Med. Microbiol., 4, 461.

Thomlinson, J. R., AND Buxton, A. 1962. A comparison of experimental anaphylactic shock in guinea-pigs with naturally-occurring oedema disease and haemorrhagic gastroenteritis in pigs. Res. Vet. Sci., 3, 186.

Thomlinson, J. R., AND Buxton, A., 1963. Anaphylaxis in pigs and its relationship to the pathogenesis of oedema disease and gastro-enteritis associated with Escherichia coli. Immunology, 6, 126. 